FLAVIA VENETUCCI GOUVEIA

\title{
ESTUDO NEUROQUÍMICO DO NUCLEO PRÉ-MAMILAR VENTRAL \\ NOS ANIMAIS SUBMISSOS DURANTE OS ENCONTROS AGONÍSTICOS SOCIAIS
}

Dissertação de Mestrado apresentada ao Instituto de Ciências Biomédicas da Universidade de São Paulo, para obtenção do Título de Mestre em Ciências Morfofuncionais. 


\section{FLAVIA VENETUCCI GOUVEIA}

\section{ESTUDO NEUROQUÍMICO DO NUCLEO PRÉ-MAMILAR VENTRAL NOS ANIMAIS SUBMISSOS DURANTE OS ENCONTROS AGONÍSTICOS SOCIAIS}

Dissertação de Mestrado apresentada ao Instituto de Ciências Biomédicas da Universidade de São Paulo, para obtenção do Título de Mestre em Ciências Morfofuncionais.

Área de Concentração:

Ciências Morfofuncionais

Orientador:

Prof. Dr. Newton Sabino Canteras 
DADOS DE CATALOGAÇÃO NA PUBLICAÇÃO (CIP)

Serviço de Biblioteca e Informação Biomédica do

Instituto de Ciências Biomédicas da Universidade de São Paulo

(C) reprodução total

Gouveia, Flavia Venetucci.

Estudo neuroquímico do núcleo pré-mamilar ventral nos animais submissos durante os encontros agonísticos sociais / Flavia Venetucci Gouveia. -- São Paulo, 2009.

Orientador: Newton Sabino Canteras.

Dissertação (Mestrado) - Universidade de São Paulo. Instituto de Ciências Biomédicas. Departamento de Anatomia. Área de concentração: Ciências Morfofuncionais. Linha de pesquisa: Análise hodológica, neuroquímica e funcional dos sistemas neurais envolvidos na organização dos comportamentos motivados.

Versão do título para o inglês: Neurochemic study of the premammillary ventralis nucleus on submissive animals during social agonistic encounters.

Descritores: 1. Hipotálamo 2. Agressão 3. Mecanismos de defesa 4. Dominação-Subordinação 5 . Óxido Nítrico 6. Transcrito regulado pela cocaína e amfetamina I. Canteras, Newton Sabino II. Universidade de São Paulo. Instituto de Ciências Biomédicas.

Programa de Pós-Graduação em Ciências Morfofuncionais III. Título. 
Candidato(a): $\quad$ Flavia Venetucci Gouveia.

Título da Dissertação: Estudo neuroquímico do núcleo pré-mamilar ventral nos animais submissos durante os encontros agonísticos sociais .

Orientador(a): $\quad$ Newton Sabino Canteras.

A Comissão Julgadora dos trabalhos de Defesa da Dissertação de Mestrado, em sessão pública realizada a ...................................,
( ) Aprovado(a)
( ) Reprovado(a)

Examinador(a): Assinatura:

Nome:

Instituição:

Examinador(a): Assinatura:

Nome:

Instituição:

Presidente: Assinatura:

Nome:

Instituição: 
Aos meus pais que me guiaram até aqui, ao meu noivo pelo apoio e compreensão e ao meu filho que logo chegará ao mundo. 


\section{AGRADECIMENTOS}

Ao meu orientador Dr. Newton Sabino Canteras, pelas oportunidades que me foram dadas e pelo grande aprendizado que esta jornada me proporcionou.

Ao Prof. Dr. Jackson Cioni Bittencourt por seus conselhos, participação nas diversas bancas avaliadoras deste trabalho e por ter permitido a utilização de seu laboratório para realização de parte de meu trabalho.

A Prof. Dr. Carol F. Elias pelo auxílio na Hibridização in situ e disponibilização de sondas.

A Simone Cristina Motta pela importante ajuda no desenvolvimento deste trabalho.

A Amanda Ribeiro de Oliveira por sua valiosa contribuição.

A Joelcimar Martins da Silva e José Donato Junior pela ajuda com a hibridização in situ.

A Luciane Valéria Sita pelos ensinamentos no processamento e contagem das lâminas.

Aos colegas de laboratório e de departamento pelo convívio harmonioso.

Aos professores membros da banca de qualificação, Dr. Cristóforo Scavone e Dr. Martin Andreas Metzger pelas preciosas recomendações.

Aos professores membros da banca de defesa Dr. Cristóforo Scavone, Dr. Martin Andreas Metzger, Dr. Luciano Freitas Felício e Dr. Gilberto Fernando Xavier.

A amiga Raquel Chacon Ruiz Martinez por sua amizade e companheirismo e por sua enorme ajuda na realização deste trabalho.

Aos amigos Eduardo Ferreira de Carvalho Netto e João Gimenez Junior por toda a ajuda e pelas ótimas conversas e conselhos.

Aos meus pais Agostinho H. Teixeira de Gouveia e Donatella V. Gouveia pelo apoio e conselhos preciosos.

Aos meus irmãos Adriano V. Gouveia e Gabriela V. Gouveia pelo carinho e amizade.

Ao meu noivo Fabio Lago Meirelles por seu amor e companheirismo.

As secretárias do Departamento de Anatomia do Instituto de Ciências Biomédicas da Universidade de São Paulo, Cristiane Vitor Pinheiro, Maria Cristina dos Santos Faustino e, em especial, Patrícia Rodrigues de Campos Rocha pela prontidão e auxílio. 
Aos funcionários do Biotério do Departamento de Anatomia do Instituto de Ciências Biomédicas da Universidade de São Paulo, Alessandro Rodrigo Martins, Fábio França Luiz e Renivaldo de Souza pelo apoio e serviço prestado.

Aos funcionários da Biblioteca do Instituto de Ciências Biomédicas da USP pela assistência prestada, tanto na busca pelo acervo como pela correção final deste trabalho.

Aos funcionários do Departamento de Anatomia do Instituto de Ciências Biomédicas III da Universidade de São Paulo e aos funcionários dos demais departamentos do Instituto de Ciências Biomédicas da Universidade de São Paulo

A Fundação de Amparo a Pesquisa do Estado de São Paulo (FAPESP) pela bolsa concedida.

E meus cordiais agradecimentos as pessoas que contribuíram para a realização deste trabalho e que os nomes estão aqui omitidos. 
"A mente que se abre a uma nova idéia jamais voltará ao seu tamanho original."

Albert Einstein 


\section{RESUMO}

GOUVEIA, F.V. Estudo neuroquímico do núcleo pré-mamilar ventral nos animais submissos durante os encontros agonísticos sociais. $200943 \mathrm{f}$. Dissertação (Mestrado em Ciências Morfofuncionais) - Instituto de Ciências Biomédicas, Universidade de São Paulo, São Paulo, 2009.

O comportamento agressivo é etologicamente observado em animais e ocorre quando os interesses de um ou mais indivíduos entram em conflito. O território é um desses interesses e, através do paradigma residente-intruso, é possível observar a expressão de comportamentos agonísticos sociais nos animais envolvidos. O comportamento de dominância vem sendo estudado sob diversos ângulos e pode ser aumentado pela presença da fêmea, de suas pistas olfativas e pelo comportamento de cópula. No hipotálamo, há o núcleo pré-mamilar ventral (PMv), ligado a um sistema sexualmente dimórfico e relacionado a comportamentos reprodutivos e agonísticos sociais. Este núcleo foi sugerido estando envolvido na modulação da agressividade ofensiva e, seus neuropeptídeos podem ter uma relação direta com a expressão desses comportamentos agonísticos. Machos expostos ás pistas olfativas da fêmea, apresentam um aumento na expressão de CART (Cocaine and Anphetamine Regulated Transcript) no PMv. Já animais knockout de Sintase do Óxido Nítrico (NOS), apresentam comportamento agressivo exacerbado e não cessam os ataques como fazem os animais controle. Através da técnica de hibridização in situ, foi estudado a expressão do RNAm de CART e de NOS nos animais intrusos expostos ao paradigma. Foram formados dois grupos, um apresentando experiência sexual prévia ao encontro agonístico e outro sem experiência sexual (naive). Foi observado um aumento na expressão de CART no grupo que apresentava comportamento de cópula previamente ao encontro agonístico. Ainda, estes animais se comportam de maneira diferente a intrusos naive, uma vez que não apresentam posturas de submissão frente ao residente e passam a buscar a dominância. Interessante observar que este aumento de neuropeptídeo é específico, uma vez que os níveis de NOS não se alteraram nos grupos analisados. Correlacionando-se CART aos comportamentos, sugere-se que a experiência sexual esteja relacionada ao aumento da expressão do CART no PMv, e possivelmente perda dos comportamento de subordinação e aumento da disputa pela dominância.

Palavras-chave: Hipotálamo. Agressão. Mecanismos de Defesa. DominaçãoSubordinação. Oxido Nítrico. Transcrito regulado pela cocaína e anfetamina. 


\begin{abstract}
GOUVEIA, F.V. Neuochemic study of the premammilary ventralis nucleus on submissive animals during agonistic social encounters. 2009. 43 p. Master thesis (Morfofunctional Sciences) - Instituto de Ciências Biomédicas, Universidade de São Paulo, São Paulo, 2009.

Aggressive behavior occurs when the interests of one or more individuals conflict. Territory is one of these interests, and the resident intruder paradigm is widely used to observe the expression of social agonistic behaviors. The dominance behavior has been studied under several views and it was shown that it can be raised by the presence of the female, its olfactory clues and by the sexual behavior. In the hypothalamus there is the premammillary ventralis nucleus (PMv) connected to a sexual dimorphic system and related to reproduction and agonistic behaviors. This nucleus was suggested as being involved in the modulation of aggressive behavior, and PMv's neuropeptides can have a direct relation with the expression of those agonistic behaviors. Males exposed to female's olfactory clues show an increase in the expression of CART (C Cocaine and Amphetamine Regulated Transcript) in the PMv. Nitric oxide synthase (NOS) knockout animals show increased aggression. In the present investigation, using in situ hybridization we studied the expression of the mRNA of CART and NOS on intruders exposed to the resident-intruder paradigm. Two experimental groups were examined: one with sexual experience before the agonistic encounter and other naïve. It was observed increased expression of CART in the PMv in the sexual-experienced intruder. More, these animals behaved differently from naive intruders, and did not display submissive postures and start searching for dominance. Sexual experienced intruders presented increased expression of CART, but not NOS, mRNA. Thus, suggesting that the sexual experience is related to an increase in CART expression in the PMv and possibly with the lost of submissive behavior and increased search for dominance status.
\end{abstract}

Keywords: Hypothalamus. Agression. Defense Machanismis. DominanceSubordination. Nitric Oxide. Cacaine and Amphetamine Regulated Trasncript. 


\section{LISTA DE ILUSTRAÇÕES}

Figura 1. Quantificação da densidade óptica integrada resultante da Hibridização in situ para verificação da expressão de RNAm de CART no núcleo Pré-Mamilar ventral.

Figura 2. Fotomicrografia em campo escuro mostrando 0 sinal de hibridização de CART no núcleo pré-mamilar ventral......................

Figura 3. Quantificação da densidade óptica integrada resultante da Hibridização in situ para verificação da expressão de RNAm de nNOS no núcleo Pré-Mamilar ventral

Figura 4. Análise comportamental dos grupos Intruso e Intruso experiente durante período de 5 minutos de observação após o ataque inicial do residente. 


\section{LISTA DE TABELAS}

Tabela 1. Análise comportamental dos grupos Intruso e Intruso experiente, durante período de 5 minutos de observação. 
1 INTRODUÇÃO

1.1 COMPORTAMENTO AGRESSIVO E DEFENSIVO................................ 13

1.2 SUBSTRATO NEURAL DO COMPORTAMENTO AGONÍSTICO SOCIAL..... 13

1.3 NEUROQUÍMICA DO PMV............................................................. 15

1.3.1 Cocaine and Amphetamine Regulated Trascripit (CART) ................... 16

1.3.2 Sintase do Óxido Nítrico Neuronal (nNOS) ......................................... 20

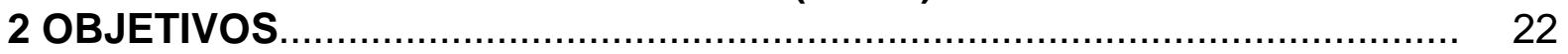

2.1 OBJETIVOS GERAIS................................................................. 22

2.2 OBJETIVOS ESPECÍFICOS.......................................................... 22

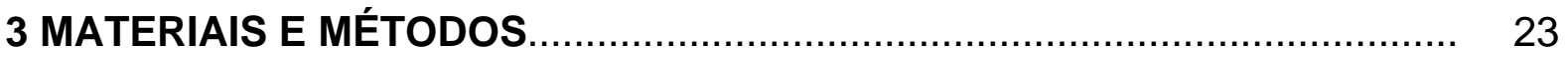

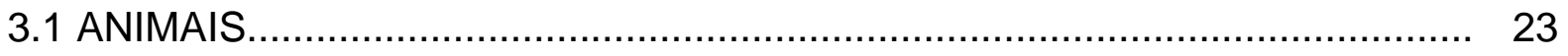

3.2 CIRURGIA DE LAQUEADURA...................................................... 23

3.3 PARADIGMA RESIDENTE-INTRUSO .............................................. 23

3.3.1 Paradigma Residente Intruso para obtenção de Intrusos naive........... 24

3.3.2 Paradigma Residente - Intruso para Intrusos Sexualmente Experientes.

3.4 PERFUSÃO E HISTOLOGIA........................................................ 24

3.5 COLORAÇÃO POR TIONINA (MÉTODO DE NISSL).............................. 25

3.6 HIBRIDIZAÇÃO "IN SITU" PARA LOCALIZAÇÃO E QUANTIFICAÇÃO DO RNAm DE CART E nNOS

3.7 ANÁLISE DOS RESULTADOS E PRODUÇÃO DE IMAGENS...................... 27

3.8 ANÁLISE ESTATÍSTICA................................................................ 27

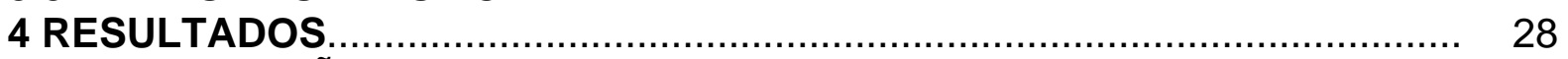

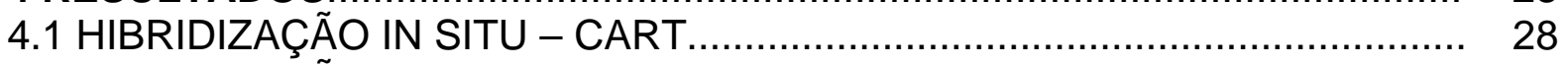

4.2 HIBRIDIZAÇÃO IN SITU - NOS....................................................... 29

4.3 ANÁLISE COMPORTAMENTAL...................................................... 30

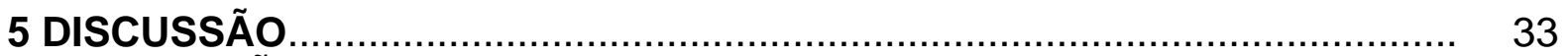

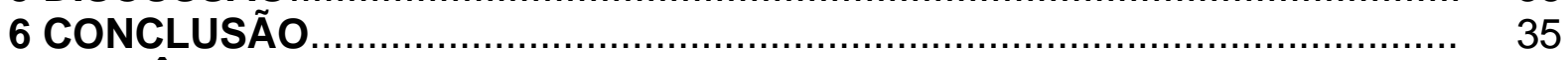

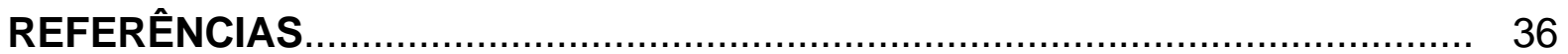




\section{INTRODUÇÃO}

\subsection{COMPORTAMENTO AGRESSIVO E DEFENSIVO}

A agressividade, caracterizada por condutas hostis, é etologicamente observada entre animais co-específicos para proteção de território, imposição de papéis hierárquicos, dominância sobre fêmeas férteis, bem como proteção da prole, ou seja, o comportamento agressivo é exibido quando os interesses de dois ou mais indivíduos entram em conflito. Em qualquer das situações, não há desejo do animal agressor de eliminar o opositor, mas sim de impor limites (PARMIGIANI et al., 1998; EIBL-EIBESFELDT, 1977).

Um tipo de agressão amplamente estudado na pesquisa animal é a territorial, sendo o paradigma residente-intruso um dos modelos melhor estabelecido e vastamente utilizado. Neste, um rato intruso e não familiar é colocado na gaiola moradia do rato residente (dominante) desencadeando ações investigatórias e ofensivas desse e, conjuntamente, ações defensivas do intruso (BLANCHARD et al., 1977; BLANCHARD; BLANCHARD, 1977).

O animal dominante, inicialmente, adota comportamentos investigatórios farejando a região inguinal do intruso, seguido de piloereção e ranger dos dentes. Seguem-se, então, comportamentos agressivos do residente como ataque lateral (lateral attack) caracterizado pela movimentação lateral do dominante ao redor do intruso; manter-se sobre o intruso (on top) quando este se encontra deitado no chão e com o ventre exposto; e a mordida, que, quando bem sucedida, finaliza o ataque. Após certo período esses ataques são cessados e a nova expressão desses pode ocorrer em decorrência de comportamentos do intruso. Quanto ao local das mordidas, foi observado que o animal dominante apresenta uma restrição biológica quanto às áreas a serem atingidas, atacando preferencialmente o dorso do intruso e ocasionalmente o ventre e região inguinal (BLANCHARD et al., 1977; BLANCHARD; BLANCHARD, 1977).

O rato intruso expressa comportamentos exploratórios e, em resposta a comportamentos agressivos do residente, posturas defensivas que dificultam a conclusão do ataque, isto é, posição de boxing ou upright, onde o animal se mantém em pé, sobre as patas traseiras movimentando, ou não, as patas dianteiras; on the back, considerada uma postura totalmente submissa, onde o animal fica deitado 
com o dorso voltado ao chão e o ventre exposto; e em posição estática (freezing), freqüente nos intervalos dos ataques. É comum o animal aprender que posições defensivas estáticas aumentam a latência dos ataques, mantendo-se, então, mais tempo sem se mover (BLANCHARD; BLANCHARD, 1977).

\subsection{SUBSTRATO NEURAL DO COMPORTAMENTO AGONÍSTICO SOCIAL}

Diversos estudos têm investigado o substrato neural do comportamento agressivo. Em 1971, Adams observou a abolição de comportamentos agressivos após lesões eletrolíticas da área do hipotálamo lateral. Esses achados foram posteriormente corroborados por Koolhaas (1978) que observou aumento dos comportamentos de luta após estimulação elétrica dessa mesma região do hipotálamo lateral. Esta região corresponde ao local do hipotálamo lateral no qual as respostas de ataque podem ser obtidas com menor limiar de estimulação e foi denominada de área hipotalâmica de ataque (ROELING et al., 1994).

Lesões eletrolíticas que incluem a região posterior do núcleo ventromedial do hipotálamo $(\mathrm{VMH})$, a região pré-mamilar e parte da região mamilar, aumentam a expressão de comportamentos agressivos tais como: ataque lateral, freqüência de mordidas e manter-se sobre o intruso (OLIVIER, 1977; OLIVIER et al., 1983). Os mesmos efeitos de aumento da agressividade ofensiva foram obtidos com lesões eletrolíticas mais circunscritas ao núcleo pré-mamilar ventral (PMv) (VAN DEN BERG et al.,1983). Nesses casos foram observados que os animais lesados não cessavam os ataques aos intrusos após a exposição, como ocorre em animais intactos. Esses dados sugerem uma participação importante desse núcleo na modulação da agressividade (VAN DEN BERG et al., 1983).

Estudos de mapeamento funcional utilizando a expressão da proteína Fos revelam que durante a interação agonística existe mobilização de diversos sítios neurais sexualmente dimórficos, também implicados na organização do comportamento de cópula. Assim, Kollack-Walker e Newman (1995) observaram, em hamsters, após a interação agonística uma mobilização significativa da porção ventrolateral do $\mathrm{VMH}$, núcleo pré-mamilar ventral, divisão posterior do núcleo intersticial da estria terminal, núcleo medial da amígdala, área amígdalo-hipocampal e núcleo cortical posterior da amígdala. Embora neste trabalho os autores não notassem diferença no padrão de expressão da proteína Fos entre o residente e 
intruso, em trabalho subseqüente (KOLLACK-WALKER et al., 1997) investigando a expressão do RNAm do gene c-fos, observou-se que os animais subordinados apresentavam maior mobilização de diversos sítios neurais relacionados ao circuito dimórfico, como a parte ventrolateral do $\mathrm{VMH}$ e área amigdalo-hipocampal, bem como o núcleo arqueado.

Observações recentes de nosso laboratório, em ratos Long Evans, corroboram os achados anteriores e mostram, durante a interação agonística, um aumento da expressão da proteína Fos na área amígdalo-hipocampal, no núcleo medial da amígdala, na parte posterior do núcleo intersticial da estria terminal, na parte lateral do $\mathrm{VMH}$, no núcleo arqueado e no núcleo pré-mamilar ventral. De particular interesse, notamos nos intrusos uma maior ativação do núcleo pré-mamilar ventral quando comparados aos residentes.

Estes resultados são bastante atrativos considerando que lesões que incluem o núcleo pré-mamilar ventral aumentam o comportamento ofensivo (VAN DEN BERG et al., 1983), sugerindo que este sítio possa modular a expressão deste comportamento. O papel desse núcleo parece ser extremamente relevante durante 0 confronto agonístico de modo que é necessário entender a neuroquímica do núcleo para tentar compreender por quais mecanismos estes comportamentos são modulados.

\subsection{NEUROQUÍMICA DO PMV}

Do ponto de vista neuroquímico, o PMv apresenta neurônios que expressam sintase do óxido nítrico (NOS) (VICENT e KIMURA, 1992) e CART (Cocaine and Amphetamine Regulated Transcript) (KOYLU et al., 1997; RONDINI et al., 2004; VRANG , 2006).

Interessantemente, Nelson e colaboradores (1995) apresentam uma relação entre a expressão de NOs e a agressividade observada nos animais. Ao estabelecerem colônias de camundongos geneticamente modificados, apresentando deleção do gene nNOs, notaram um aumento de agressividade e uma constante morte de indivíduos da mesma colônia, indicando que estes freqüentemente iniciavam embates entre si. Ao colocar estes animais no paradigma residente intruso, observaram um aumento significante na freqüência dos ataques do residente ao intruso quando comparados com animais normais. 
A presença da fêmea, de suas pistas olfativas e o comportamento sexual aumentam os níveis plasmáticos de testosterona em machos e são fundamentais para a modulação da agressividade. Animais residentes que copulam antes do encontro agonístico apresentam mais expressão de comportamentos agressivos, com freqüência de ataques e numero de mordidas maior (MACRIDES et al.,1975; KAMEL et al., 1977; PURVIS et al., 1978; FLANNEELLY et al., 1982; GOYENS et al., 1975). Estas informações da fêmea ainda influenciam a expressão de CART no PMv, indicando que este neuropeptídeo está relacionado com o comportamento sexual (CAVALCANTE et al., 2006).

\subsubsection{Cocaine and Amphetamine Regulated Trascripit (CART)}

CART foi identificado pela primeira vez por Spiess e colaboradores (1981), a partir de extratos do hipotálamo de ovelhas e parcialmente seqüenciado, mas sua função e significância não foram percebidas até que, em 1995 James Douglass e colaboradores notaram a elevação de sua expressão a partir da administração de drogas psicoestimulantes, como a cocaína e a anfetamina. Já completamente seqüenciado, apresenta um conjunto de 27 amino ácidos indicando que faz parte de vias secretoras. Em ratos, apresenta duas formas de splice alternativos, diferentes entre si em 39 nucleotídeos que pode gerar dois peptídeos resultantes, um longo contendo 129 amino ácidos ou um curto com 116 amino ácidos. Ambos os fragmentos são derivados de uma forma longa do RNAm de CART e em seres humanos somente é encontrado a forma curta do peptídeo (DOUGLASS et al., 1995; KUHAR et al., 2000; KUHAR et al., 2002).

Desde sua descoberta, muitas funções e aplicações já foram descritas para CART. Por estar presente em núcleos específicos no sistema mesolímbico (sistema de recompensa), no sistema neuroendócrino, principalmente hipotálamo, e ser encontrado pelo eixo hipotálamo - hipófise - adrenal (HPA), os estudos envolvendo CART voltam-se sempre para a investigação de processos e comportamentos que são de responsabilidade dessas áreas (ROGGE et al., 2008; DOUGLASS et al., 1995; KOYLU et al., 1997).

Experimentos que levaram a descoberta de CART envolviam substâncias como cocaína e anfetamina no núcleo estriado de ratos e resultou na elevação de sua transcrição (DOUGLASS et al., 1995). Apesar de estes dados não serem 
sempre reproduzidos (VRANG et al., 2002; MARIE-CLAIRE et al., 2003), formou-se o conceito de que este peptídeo estaria envolvido com sistemas responsáveis pela dependência e abuso de drogas. Neuroanatomicamente, CART é expresso em neurônios no núcleo acumbens, e é encontrado, também, em botões terminais desses neurônios na área Tegmental Ventral (VTA). No hipotálamo lateral ocorre o mesmo: neurônios apresentando CART projetam-se para VTA (DALLVECHIAADAMS et al., 2001, 2002; SMITH et al., 1999).

A injeção de CART no VTA leva a um efeito similar, porém menor, a de uma droga psicoestimulante, aumenta a atividade locomotora dos animais e é capaz de produzir preferência condicionada de lugar. Esse efeito de aumento de locomoção pode ser inibido pela administração prévia de antagonista de receptor dopaminérgico, haloperidol (KIMMEL et al., 2000). Já a injeção de CART no núcleo acumbens, por si só, não altera a atividade locomotora, mas, quando injetado concomitantemente com drogas psicoestimulantes, diminui a atividade locomotora geral induzida por drogas (JAWORSKI et al., 2003; KIM et al., 2003). Em estudo de auto-administração de cocaína, a injeção no núcleo acumbens de CART levou a diminuição do efeito reforçador da droga (JAWORSKI et al., 2008). Já em humanos, estudos com tecidos post mortem de vitimas de overdose de cocaína, foram observadas elevações nos níveis deste peptídeo no núcleo acumbens e diminuições do mesmo no VTA (ALBERTSON et al., 2004; TANG et al., 2003). Estes trabalhos sugerem que, neste núcleo, CART estaria atuando como um regulador homeostático, diminuindo tanto o efeito de drogas, como seu valor reforçador e motivacional (ROGGE et al., 2008; JAWORSKI et al., 2008; DOMINGUEZ et al., 2004).

Não se sabe ao certo como CART modula estes núcleos e seu papel em relação à dopamina ou a GABA, porém, a partir de achados revelando a presença de receptores dopaminérgicos em células que contém CART (BEAUDRY et al., 2004; HUBERT et al., 2006), suas projeções para neurônios dopaminérgicos da VTA (DALLVECHIA-ADAMS et al., 2001, 2002) e considerando a elevação de dopamina extracelular decorrente do uso de drogas psicoativas no núcleo acumbens (PETTIT et al., 1990), pode-se sugerir que ocorre ativação de células que contém CART no núcleo acumbens e que estas, projetando-se diretamente para VTA, regulam a atividade dopaminérgica local (KUHAR et al., 2002). Em relação ao GABA, grande parte das projeções acumbens/VTA alcançam células GABAérgicas e portanto 
poderiam, também, controlar a transmissão dopaminérgica a partir da inibição de interneurônios GABA (KUHAR et al., 2002; ROGGE et al., 2008; DOMINGUEZ et al., 2004).

Com a descrição dos núcleos cerebrais que expressam CART, entre estes, arqueado, hipotálamo lateral, paraventricular e acumbens, surgiu a hipótese de que CART estaria relacionado com alimentação e controle do peso corpóreo (KOYLU et al., 1997, 1998). Trabalhos realizados com injeção intra-cerebro-ventricular (ICV) de fragmentos do peptídeo CART mostraram diminuição na ingestão alimentar, e, em contraste, estudos utilizando anticorpos contra estes fragmentos de CART, injetados pela mesma via, revelaram aumento na ingestão de alimentos, indicando que este peptídeo exerce um controle inibitório na alimentação (KRISTENSEN et al., 1998; LAMBERT et al., 1988; BANNON et al., 2001). Porém, nestes estudos foram relatados, também, posturas incomuns, tremores e aumento no comportamento de lamber, portanto, não se sabe ao certo se CART é realmente um peptídeo anorexigênico ou se a inibição da alimentação é um fator secundário a outros efeitos (KUHAR et al., 2002).

Demais estudos ainda mostram que a administração ICV de fragmentos desse peptídeo inibe a alimentação induzida pelo Neuropeptídeo $\mathrm{Y}$, um dos principais estimulantes centrais do comportamento alimentar (KRISTENSEN et al., 1998; CLARK et al., 1984). Há relatos, também, de que administração crônica de CART não só diminui a ingestão alimentar como o peso corpóreo, tanto de ratos magros quanto de ratos obesos da linhagem Zucker, quadro este, que é revertido com a descontinuação da administração do peptídeo (LARSEN et al., 2000).

Outro indício da relação de CART e o comportamento alimentar é sua ligação com a leptina, um hormônio secretado por adipócitos que parece ser um dos mais potentes reguladores desse peptídeo no hipotálamo (KRISTENSEN et al., 1998). Elias e colaboradores (2000) demonstraram a co-localização entre imunorreatividade para Fos e transcrição de CART em neurônios ativados por leptina nos núcleos retroquiasmático, arqueado, premamilar ventral e dorsal-medial. Assim, trabalhos realizados com camundongos $\mathrm{Ob} / \mathrm{Ob}$, uma linhagem geneticamente modificada que apresenta deficiência de leptina, e ratos Zucker, deficientes de receptor de leptina, mostraram redução significante de RNAm de CART em diversos sítios hipotalâmicos. Em camundongos $O b / O b$, a injeção intraperitoneal de leptina recombinante leva ao aumento da expressão do RNAm de CART no núcleo 
arqueado e hipotálamo lateral (KRISTENSEN et al., 1998; LARSEN et al., 2000). Ainda, estudos mostram que injeções de leptina aumentam a expressão de Fos em células hipotalâmicas que contém CART e que estas possuem receptores para leptina (ELIAS et al., 1998).

Outro grande foco de atenção para CART é sua ligação com as respostas de estresse. Localizado nos principais núcleos relacionados com a modulação da resposta de estresse, como o núcleo arqueado, o núcleo paraventricular do hipotálamo (PVN), a amígdala e, principalmente, por todo o eixo HPA (hipotálamohipófise-adrenal), sua correlação com hormônios gluclocorticóides e adrenalina, sabidamente envolvidos nas respostas de estresse, são de particular interesse (KOYLU et al., 1997; STANLEY et al., 2001). A maioria dos neurônios que contém CRF (fator de liberação de corticotropina) no núcleo paraventricular do hipotálamo exibe FOS em resposta a administração ICV de fragmentos do peptídeo CART, e este leva, ainda, a aumento nos níveis plasmáticos de hormônio adrenocorticotrópico (ACTH) e corticosterona, sugerindo seu envolvimento na modulação da liberação de CRF (STANLEY et al., 2001; VRANG et al., 2000). Smith e colaboradores (2004) sugeriram que CART regularia a atividade do eixo HPA a partir do um mecanismo central dependente de CRF e, em outro trabalho, foi observado que, a partir de estresse de hipotensão, CART é encontrado no sangue portal da glândula pituitária (LARSEN et al., 2003). Em estudo investigando o envolvimento de CART com a glândula adrenal, utilizando cirurgia de adrenalectomia, foi evidenciada uma significante redução do número de células que expressam CART no PVN e a reposição com glucocorticóides reverteu parcialmente essa redução (SAVONTAUS et al., 2002; BALKAN et al., 2003; VRANG et al., 2003). A injeção intraperitoneal de corticosterona aumenta os níveis séricos de CART e a administração de Metyrapone, um inibidor da síntese de coritcosterona, reverte esse quadro (VICENTIC et al., 2005).

CART ainda se co-localiza com células do PVN que expressam Óxido Nítrico, um neurotransmissor gasoso que tem sua expressão aumentada quando 0 organismo é colocado em situação de estresse. Este estimula células do PVN e sofre regulação negativa por glicocorticóides em um sistema de retroalimentação (feedback). Sua interação com o CART ainda não é totalmente clara, mas supõe-se que são liberados conjuntamente para modular a função neuroendócrina (LOPEZFIGUEROA et al., 1998; MCCANN et al., 1996; KOYLU et al., 2000, 2006). 
Outra implicação interessante de CART é sua ligação com a ansiedade e depressão. Kask e colaboradores em 2000 revelaram que administração ICV de fragmento CART levou a atividade ansiogênica em ratos no labirinto em cruz elevado, ficando estes mais tempo nos braços fechados, sem afetar a locomoção total em campo aberto. Estes achados foram corroborados posteriormente por Asakawa e colaboradores (2001) e novamente em 2003 por Chaki e colaboradores, que, além deste, mostrou diminuição significante nos parâmetros observados no teste de interação social. De modo que, drogas ansiolíticas como o Diazepam revertem estes resultados.

Até o momento, não foi encontrado nenhum receptor específico para CART, ainda que os indícios de sua existência sejam vastos. Acredita-se que as técnicas atuais não sejam capazes de detectá-los por exigirem alta afinidade do ligante com seu receptor e especificidade (ROGGE et al., 2008).

CART está presente no circuito sexualmente dimórfico e têm sua expressão elevada em resposta as pistas olfativas da fêmea. Considerando a importância do PMv e da fêmea para os comportamentos agonísticos sociais da torna-se relevante investigar o papel de CART neste contexto.

\subsubsection{Sintase do Óxido Nítrico Neuronal (nNOS)}

Óxido Nítrico (NO) é um mediador gasoso de comunicação celular envolvido na regulação dos sistemas nervoso, cardiovascular e imune. Sua enzima de síntese, Sintase do Óxido Nítrico, é encontrada em três isoformas diferentes que correspondem a sintase do óxido nítrico neuronal (nNOS), sintase do óxido nítrico endotelial (eNOS) e sintase do óxido nítrico induzida (iNOS) (ZHOU; ZHU, 2009; BREDT, 1999).

O locus genômico da nNOS humana está localizado no cromossomo 12 e é distribuído em uma região de mais de 200 kb. Sua proteína é um dímero solúvel que consiste de 1434 amino ácidos com um peso preditivo de 160,8 kDa. Possui como grupos prostéticos ligados, ferro protoporfirina IX (heme), flavina adeninadinucleotídeo (FAD), flavina mononucleotídeo (FMN) e tetraidrobiopterina. Além disto, possui sítios de ligação para L-arginina, fosfato de nicotinamida adeninadinucleotídeo reduzido (NADPH) e cálcio-clamodulina (BOISSEL, et al., 1998; RANG et al., 2004). 
As enzimas nNOS combinam as atividade oxigenase e redutase associadas a domínios estruturais distintos. O domínio da oxigenase contém heme, enquanto o da resutase liga-se a cálcio-calmodulina, FMN, FAD e NADPH. Acredita-se que as flavinas aceitem elétrons do NADPH e os transfiram para o ferro hêmico que se liga ao oxigênio e catalisa a oxidação por etapas da L-arginina em NO e citrulina. A velocidade de produção de NO não é dependente da quantidade excessiva de Larginina no citoplasma, mas sim pela atividade enzimática da nNOS, apesar de doses muito altas de L-arginina ser capaz de restaurar a biossíntese normal de NO em alguns casos patológicos (RANG et al., 2004).

Uma vez produzido, o óxido nítrico atua localmente, uma vez que apresenta meia-vida curta de 5-10 segundos no espaço extracelular, antes de se converter em nitrato e nitrito pela ação do oxigênio e da água (ALBERTS et al., 2004).

Apesar de o óxido nítrico ser fundamental para a mediação de plasticidade sináptica e da sinalização neuronal, quando encontrado em quantidade excessiva torna-se neurotóxico. Portanto, acredita-se que nNOS deva ser a peça chave em uma grande variedade de condições patológicas (ZHOU; ZHU, 2009).

$\mathrm{Na}$ tentativa de elucidar os principais papéis do óxido nítrico no organismo, Nelson e colaboradores (1995) desenvolveram uma linhagem de camundongos apresentando deleção do gene para nNOS. Dentre as diversas alterações observadas nesses animais, foi notado um acentuado aumento de agressividade, notado pela constante morte de indivíduos da colônia e freqüentes embates. Colocaram, então, estes animais no paradigma residente intruso e observaram que os animais knockout do gene para nNOS apresentavam exacerbada agressividade e aumento na freqüência dos ataques quando comparados aos animais controle.

Esses dados indicam que NOS deva atuar nos sistemas relacionados à agressividade e dominância e que pode ser responsável pela modulação destes comportamentos, portanto, se torna interessante estudar sua relação com os comportamentos agonísticos sociais. 


\section{OBJETIVOS}

\subsection{OBJETIVOS GERAIS}

Pesquisar a existência de uma neuromodulação do núcleo pré-mamilar ventral, que seria responsável pela mediação das respostas observadas por intrusos no paradigma residente intruso.

\subsection{OBJETIVOS ESPECÍFICOS}

Estudar o padrão comportamental de intrusos com e sem experiência sexual prévia ao encontro agonístico.

Determinar a expressão do RNAm de CART no núcleo pré-mamilar ventral de intrusos com e sem experiência sexual prévia ao encontro agonístico.

Determinar a expressão do RNAm da Sintase do Oxido Nítrico no núcleo prémamilar ventral nos grupos supracitados. 


\section{MATERIAIS E MÉTODOS}

\subsection{ANIMAIS}

Foram utilizados ratos machos e fêmeas das linhagens Long Evans e Wistar provenientes do Instituto de Ciências Biomédicas da Universidade de São Paulo (ICB - USP), com três meses de idade, pesando entre 200 e 350 g. Os animais foram mantidos num ciclo claro/escuro de 12/12 hs, com início do período escuro às 14:00 hs, e acesso livre a ração e água. Os procedimentos foram conduzidos com base no Protocolo de Ética adotado pela Universidade de São Paulo (Protocolo 130/05/CEEA 29/11/05).

\subsection{CIRURGIA DE LAQUEADURA}

Fêmeas Long Evans com três meses de idade, pesando entre 200 - 250g foram anestesiadas via intraperitoneal com Equitesin $(0,3 \mathrm{ml} / 100 \mathrm{~g}$ de peso corpóreo). Após raspar os pêlos da região lateral do animal e limpar a pele com lodopovidona, uma incisão de $3 \mathrm{~cm}$ foi feita verticalmente, expondo a cavidade abdominal. O corno uterino foi identificado e suturado em dois pontos, distantes um $\mathrm{cm}$ do ovário e entre eles, e a região entre os pontos foi removida. A ferida cirurgica foi suturada e o mesmo procedimento foi realizado no outro corno uterino. As fêmeas tiveram uma recuperação cirúrgica de três semanas antes de serem colocadas com os machos.

\subsection{PARADIGMA RESIDENTE-INTRUSO}

Um casal de ratos Long Evans foi mantido em gaiola de acrílico (45X29X30 $\mathrm{cm}$ ), por um período de três semanas. O chão da gaiola foi coberto com serragem e limpo uma vez a cada dois dias até o $20^{\circ}$ dia de convivência. As fêmeas utilizadas foram previamente laqueadas, e seus ovários mantidos intactos para a preservação do ciclo estral e conseqüente comportamento sexual. Os testes foram realizados na primeira hora do período escuro. 


\subsubsection{Paradigma Residente Intruso para obtenção de Intrusos naive:}

No $21^{\circ}$ dia de convivência, a fêmea foi retirada e, imediatamente, um rato intruso e não familiar da linhagem Wistar foi colocado na gaiola moradia por um período de 30 minutos. Após esse encontro agonístico, o intruso foi retirado e descartado e a fêmea recolocada na gaiola juntamente com o macho residente. No $22^{\circ}$ a fêmea foi novamente retirada da gaiola moradia e um novo rato macho e intruso da linhagem Wistar foi colocado na gaiola moradia por um período de 30 minutos. Noventa minutos após o término do encontro agonístico, o intruso foi anestesiado e perfundido.

\subsubsection{Paradigma Residente - Intruso para Intrusos Sexualmente Experientes:}

Intrusos Wistar foram mantidos com fêmeas laqueadas por um período de duas semanas prévias ao encontro agonístico para realizarem o comportamento sexual. No dia do teste, estes foram colocados na gaiola moradia de um residente que estava no $22^{\circ}$ dia de convivência com sua fêmea e permaneceram por trinta minutos. Noventa minutos após o término do encontro agonístico, os intrusos foram anestesiados e perfundidos.

\subsection{PERFUSÃO E HISTOLOGIA}

Noventa minutos após o término do encontro agonístico, os animais foram anestesiados por via intraperitoneal com Hidrato de Cloral $(0,4 \mathrm{ml} / 100 \mathrm{~g}$ de peso corpóreo) e em seguida perfundidos por via transcardíaca, utilizando uma bomba peristáltica (Cole Parmer), com $150 \mathrm{ml}$ de solução de Salina 0,9\% e, em seguida, com $500 \mathrm{ml}$ de Paraformaldeío a 4\% diluído em tampão fosfato de sódio 0,1 M (pH 7,4). O animal foi mantido sob refrigeração por 3 horas e, após esse período, o encéfalo foi retirado da caixa craniana e mantido em solução de sacarose $20 \%$ em tampão fosfato de potássio $0,02 \mathrm{M}$ por aproximadamente 12 horas para crioproteção.

Utilizando um micrótomo de congelamento (Reicher-Young), foram obtidos cortes coronais seriados com $30 \mu \mathrm{m}$ de espessura e armazenados em cinco compartimentos. Um foi preparado para coloração por tionina (método de Nissl), 
como referência citoarquitetônica encefálica e os demais montados em lâminas com aderência eletrostática e armazenados em freezer $-20^{\circ} \mathrm{C}$ para posterior Hibridização "in situ".

\subsection{COLORAÇÃO POR TIONINA (MÉTODO DE NISSL)}

Os cortes histológicos de um dos compartimentos obtidos foram montados em lâminas gelatinizadas e deixados secar a temperatura ambiente por 48 horas. As lâminas foram colocadas em álcool 70\% por um período de 12 horas, e então passaram por uma bateria de álcoois e xilol (Álcool 95\% I - 3 minutos; Álcool 95\% II - 3 minutos; Álcool 100\% I - 3 minutos; Álcool 100\% II - 3 minutos; Xilol I - 3 minutos; Xilol II - 30 minutos). Depois de trinta minutos no xilol, as lâminas passaram por uma bateria de álcoois e água (Álcool 100\% II - 2 minutos; Álcool 100\% I - 2 minutos; Álcool 95\% II - 2 minutos; Álcool 95\% I - 2 minutos; Álcool 70\% - 2 minutos; Álcool 50\% - 2 minutos; Água - 2 minutos). As lâminas foram colocadas numa solução de tionina $0,25 \%$ por 18 segundos e foram submetidas a uma bateria de água, álcoois e xilol por poucos segundos em cada. (Água I; Água II; Álcool 50\%; Álcool 70\%; Álcool 95\% I; Álcool 95\% II, Álcool 100\% I; Álcool 100\% II; Xilol I) As lâminas ficaram, então, 30 minutos em Xilol II e em seguida foram cobertas com lamínula e DPX e deixadas para secar a temperatura ambiente.

\subsection{HIBRIDIZAÇÃO "IN SITU” PARA LOCALIZAÇÃO E QUANTIFICAÇÃO DO RNAm DE CART E Nnos}

Os cortes obtidos nas séries a serem submetidas à hibridação "in situ" foram montados em lâminas estéreis com aderência eletrostática (Microscopic Plus, Fisher) e secaram a temperatura ambiente por 48 horas. Foram armazenados em freezer $-20^{\circ} \mathrm{C}$ em caixa estéril contendo cápsulas de sílica para absorver a umidade, até o início do pré-tratamento. Neste, os cortes foram colocados em uma solução de formaldeído 4\% em 10x PBS durante 5 minutos e em seguida lavados em 1x PBS por 10 minutos, seguiu-se a incubação em solução de Proteinase $K(0,5 \mu \mathrm{g} / \mathrm{mL})$ contendo 0,5 M EDTA pH 8,0, $1 \mathrm{M}$ Tris- $\mathrm{HCl}$ pH 8,0 e DEPC $\mathrm{H}_{2} \mathrm{O}$ (Dietil Pirocarbonato $+\mathrm{H}_{2} \mathrm{O}$ ) por 30 minutos a $37^{\circ} \mathrm{C}$ para quebrar ligações peptídicas e aumentar a penetração da sonda. Os cortes, em seguida, foram lavados em DEPC $\mathrm{H}_{2} \mathrm{O}$ e 
ficaram em solução TEA-HCl pH 8,0 por 10 minutos. Seguiram para solução TEA-

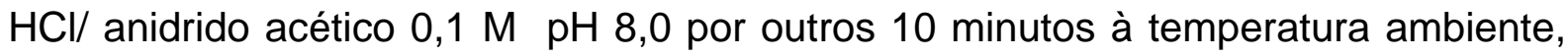
para neutralizar a possível ocorrência de íons livres e melhorar a penetração da sonda. Os cortes foram lavados em 2x Tampão Citrato de Sódio 0,3 M - Cloreto de Sódio 3 M (SSC), sendo, em seguida, iniciada a desidratação e deslipidificação dos mesmos em álcoois etílicos de concentração crescente e xilol (por 15 minutos). As lâminas secaram a temperatura ambiente por aproximadamente 30 minutos e foram acondicionadas novamente em caixas estéreis, juntamente com cápsulas de sílica e armazenadas a $-20^{\circ} \mathrm{C}$.

A sonda de nNOS e os plasmídeos contendo a sonda para CART foram gentilmente cedidos pelo Prof. Dr. Joel K. Elmquist (Center for Hypothalamic Research, Department of Internal Medicine, University of Texas Southwestern Medical Center, TX-USA).

Os plasmídeos foram linearizados através da enzima de restrição Hind III para CART (direção anti-senso) conforme orientação do laboratório de origem e isolados com fenol-clorofórmio-isoamilálcool. A sonda para nNOS foi concedida pronta para uso.

Todas as sondas foram marcadas com ${ }^{35} \mathrm{~S}$-UTP através de transcrição in vitro em nosso laboratório, usando as enzimas polimerases T3 e T7. As transcrições foram realizadas a $37^{\circ} \mathrm{C}$ por 1 hora e as sondas isoladas pela adição de $1 \mu \mathrm{L}$ de RNAsin e $1 \mu \mathrm{L}$ de RQ1 DNAse a $37^{\circ} \mathrm{C}$ por dez minutos. Em seguida os NTPs não incorporados foram removidos utilizando micro colunas de resina (Probe Quant G50). Posteriormente a este, foi feita a contagem de incorporação do ${ }^{35}$ S-UTP em aparelho de cintilação. As sondas foram então acrescentadas a um tampão de hibridização previamente preparado, contendo $50 \%$ de formamida, $20 \mathrm{mM}$ Tris- $\mathrm{HCl}$ pH 7,5, EDTA 2 mM, ditiotreito (DTT) 10 mM, 0,02\% RNA transportador de levedura, $0,1 \%$ de RNA total de levedura, $20 \%$ de sulfato de dextrana e $1 x$ solução de Denhardt e sofreram um choque térmico ( 5 minutos a $90^{\circ} \mathrm{C}$ e 5 minutos no gelo). Em seguida foram acrescentadas ao tampão $750 \mu \mathrm{L}$ de formamida 50\%, $15 \mu \mathrm{L}$ de Lauril Sulfato 10\% (SDS), $15 \mu \mathrm{L}$ de tiosulfato de sódio $10 \%$ e $30 \mu \mathrm{L}$ de 5 M DTT. A solução de hibridação contendo a sonda foi aplicada à superfície dos cortes histológicos previamente tratados. As lâminas foram cobertas com lamínulas (Sigma) e levadas à estufa de hibridização por 18 horas a $56^{\circ} \mathrm{C}$. Após este período, as 
lamínulas foram retiradas, o tampão de hibridização foi lavado e o excesso de sonda retirado com banhos em RNAase a 0,2\% e de estringência (aumento de temperatura e diminuição na concentração de sal) para retirar as possíveis hibridações inespecíficas.

Após os banhos as lâminas foram desidratadas em concentrações crescentes de álcool etílico e deixadas secar a temperatura ambiente. Foram transferidas para cassetes e, em sala escura, colocadas em contato com filme auto-radiográfico (Kodak - Biomax MR). Passados três dias, o filme foi revelado com revelador Kodak (2 minutos), água (banhos rápidos), fixador Kodak (2 minutos) e água corrente. Verificada a incorporação da sonda pelo tecido, as lâminas foram mergulhadas em emulsão fotográfica. A emulsão fotográfica (Kodak) foi, em sala escura, derretida em banho-maria a $40{ }^{\circ} \mathrm{C}$ e diluída em $50 \%$ com água destilada. As lâminas foram mergulhadas na emulsão e colocadas na estufa a $37^{\circ} \mathrm{C}$ por 3 horas antes de serem lacradas em caixas de lâminas juntamente com cápsulas de sílica e armazenadas em câmara fria a $4^{\circ} \mathrm{C}$. Após 15 dias, as lâminas foram reveladas com revelador Kodak (3 minutos), água (10 mergulhos), fixador Kodak (3 minutos) e água corrente (15 minutos). As lâminas foram desidratadas em soluções crescentes de álcool etílico e submetidas à coloração de Nissl como descrito anteriormente, deslipidificadas em xilol e cobertas com DPX e lamínula.

\subsection{ANÁLISE DOS RESULTADOS E PRODUÇÃO DE IMAGENS}

Todos os resultados foram analisados em microscópio Leica, utilizando campo claro. As imagens foram digitalizadas utilizando uma câmera Spot $\mathrm{RT}^{\circledR}$ color (Diagnostic Instruments) acoplada a um computador Dell Dimension 4400, através do programa Image Pro Plus. As figuras foram editadas utilizando os programa Photoshop 7.0 (Adobe Photoshop) e Illustrator 6.0 (Adobe Illustrator), sendo que apenas o brilho e equilíbrio de cores foram ajustados.

\subsection{ANÁLISE ESTATÍSTICA}

Os resultados foram submetidos ao teste de Levene para análise de homogeneidade e, então ao teste de Kruskal Wallis seguidos de análise em pares pelo teste de Mann-Whitney. Foi considerado nível de significância valor de $p<0,05$. 


\section{RESULTADOS}

\subsection{HIBRIDIZAÇÃO IN SITU - CART}

A hibridização in situ foi utilizada para verificar o padrão de expressão de RNAm de CART nas partes Rostral Ventral, Rostral Dorsal e Caudal do núcleo Pré Mamilar ventral dos grupos Controle, Intruso e Intruso Experiente sexualmente.

Após análise estatística dos valores obtidos a partir da densidade óptica integrada (IOD) resultante da hibridização in situ, observou-se aumento de expressão de RNAm de CART no grupo Intruso Experiente em relação aos grupos Controle e Intruso nas porções rostral ventral $(H(2,15)=9,62 p<0,01)$, rostral dorsal $(H(2,15)=12,5 p<0,01)$, caudal $(H(2,15)=9,04 p<0,02)$ e na Contagem Total $(H$ $(2,45)=27,70 p<0,01)$ do núcleo Pré-mamilar ventral (Figuras 1 e 2).

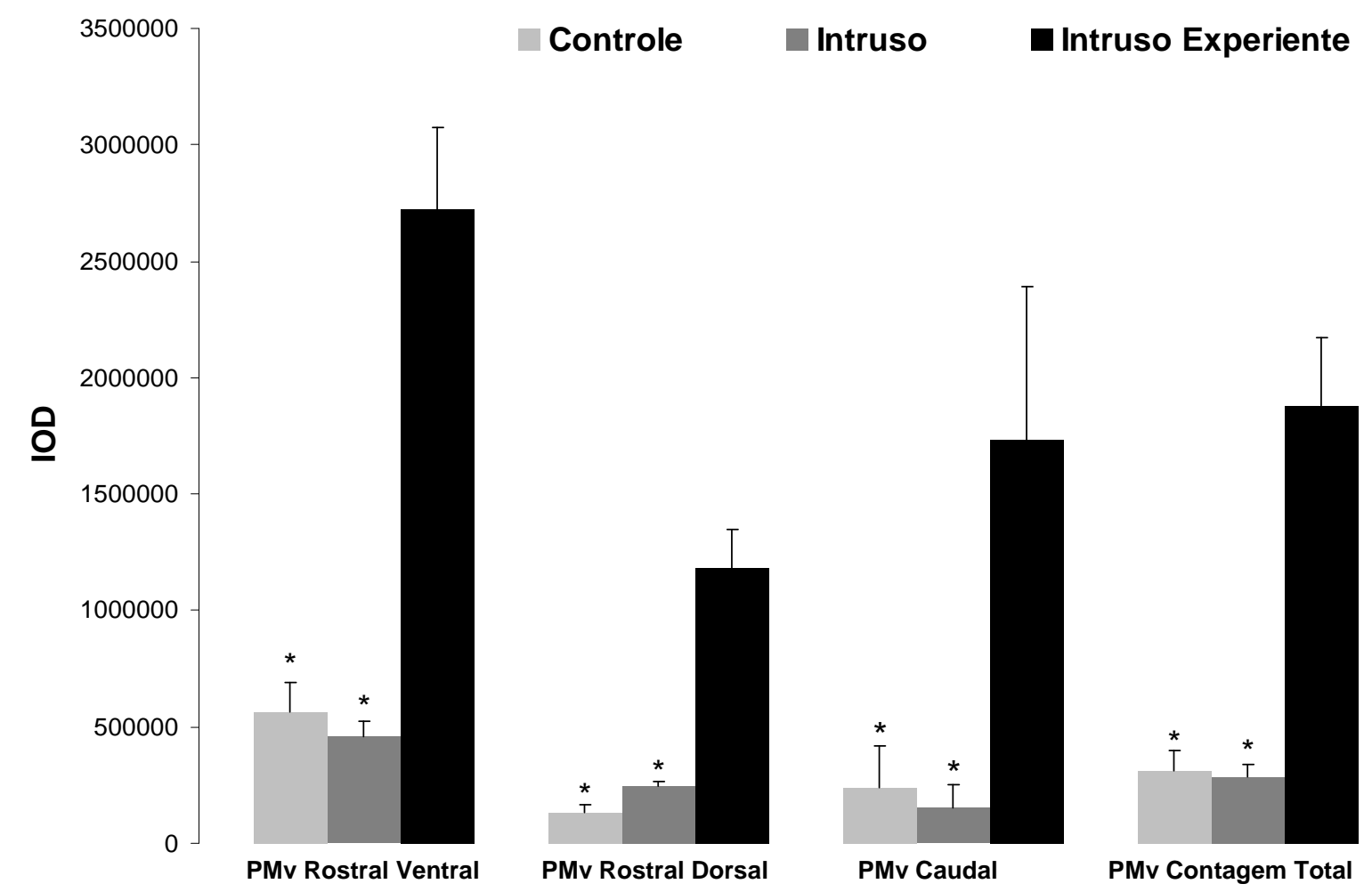

Figura 1 - Quantificação da densidade óptica integrada (IOD) resultante da Hibridização in situ para verificação da expressão de RNAm de CART no núcleo Pré-Mamilar ventral nas suas partes Rostral Ventral, Rostral Dorsal, Caudal e Contagem Total do núcleo. Dados apresentados como média ( \pm SEM). *, p < 0,05 em relação a Intruso Experiente. 

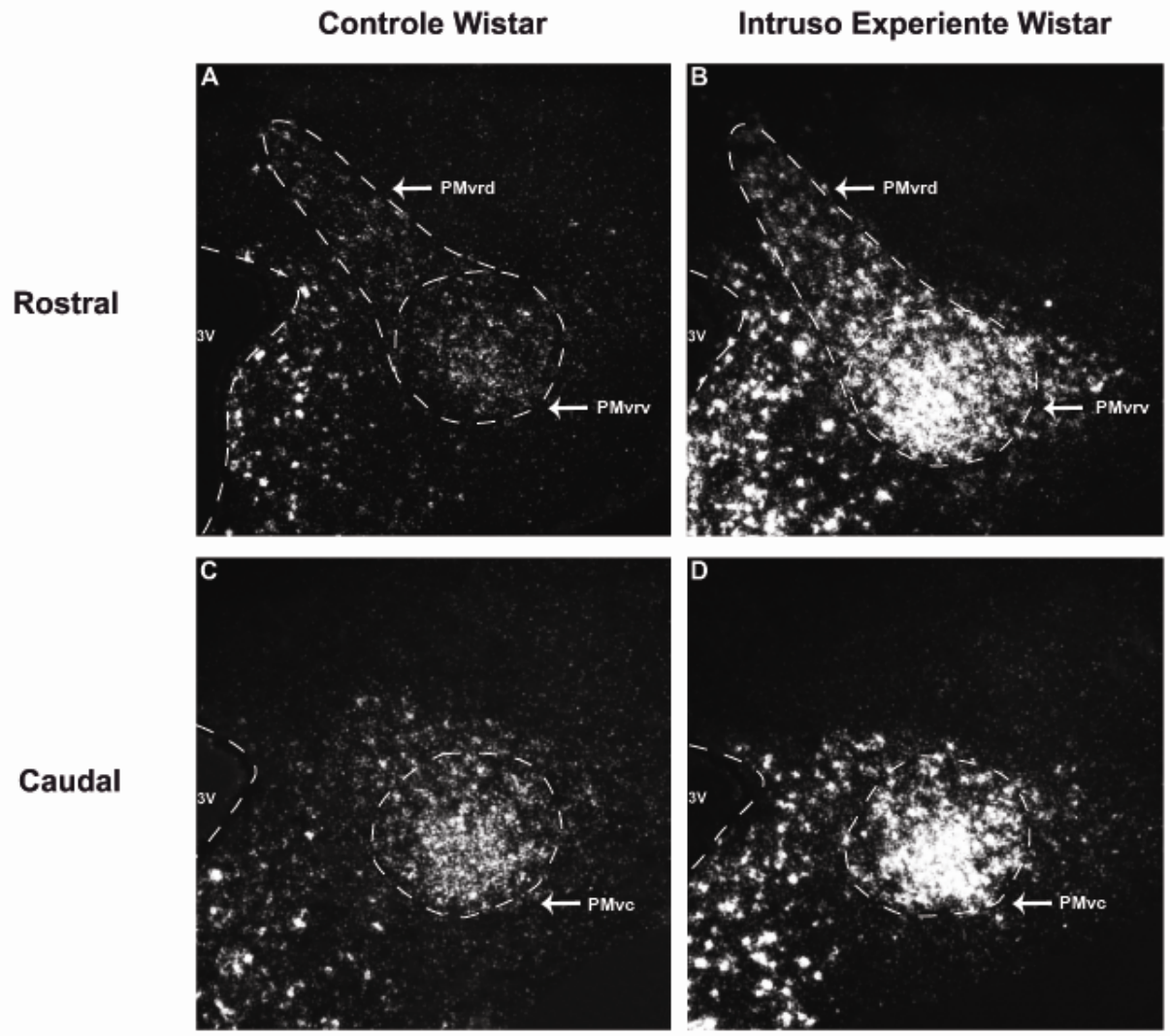

Figura 2 - Fotomicrografia em campo escuro mostrando o sinal de hibridização de CART no núcleo pré-mamilar ventral nas partes Rostral Ventral, Rostral Dorsal e Caudal. Controle (A e C), Intruso Experiente (B e D). Pontos brancos = marcação com ${ }^{35}$ S. Abreviações: $3 \mathrm{~V}=$ terceiro ventrículo/ PMvrv = núcleo pré-mamilar ventral parte rostral ventral/ $\mathbf{P M v r d ~}=$ núcleo pré-mamilar ventral parte rostral dorsal/ PMvc = núcleo pré-mamilar ventral parte caudal.

\subsection{HIBRIDIZAÇÃO IN SITU - NOS}

A hibridização in situ foi utilizada para verificar o padrão de expressão de RNAm de nNOS nas partes Rostral Ventral, Rostral Dorsal e Caudal do núcleo Pré Mamilar ventral dos grupos Controle, Intruso e Intruso Experiente sexualmente.

A análise estatística dos valores obtidos após análise da densidade óptica integrada (IOD) resultante da hibridização in situ, não mostrou diferenças significantes entres os grupos Controle, Intruso e Intruso Experiente nas porções Rostral Ventral, Rostral Dorsal e Caudal do núcleo Pré Mamilar ventral, bem como na contagem total do núcleo (Figura 3). 


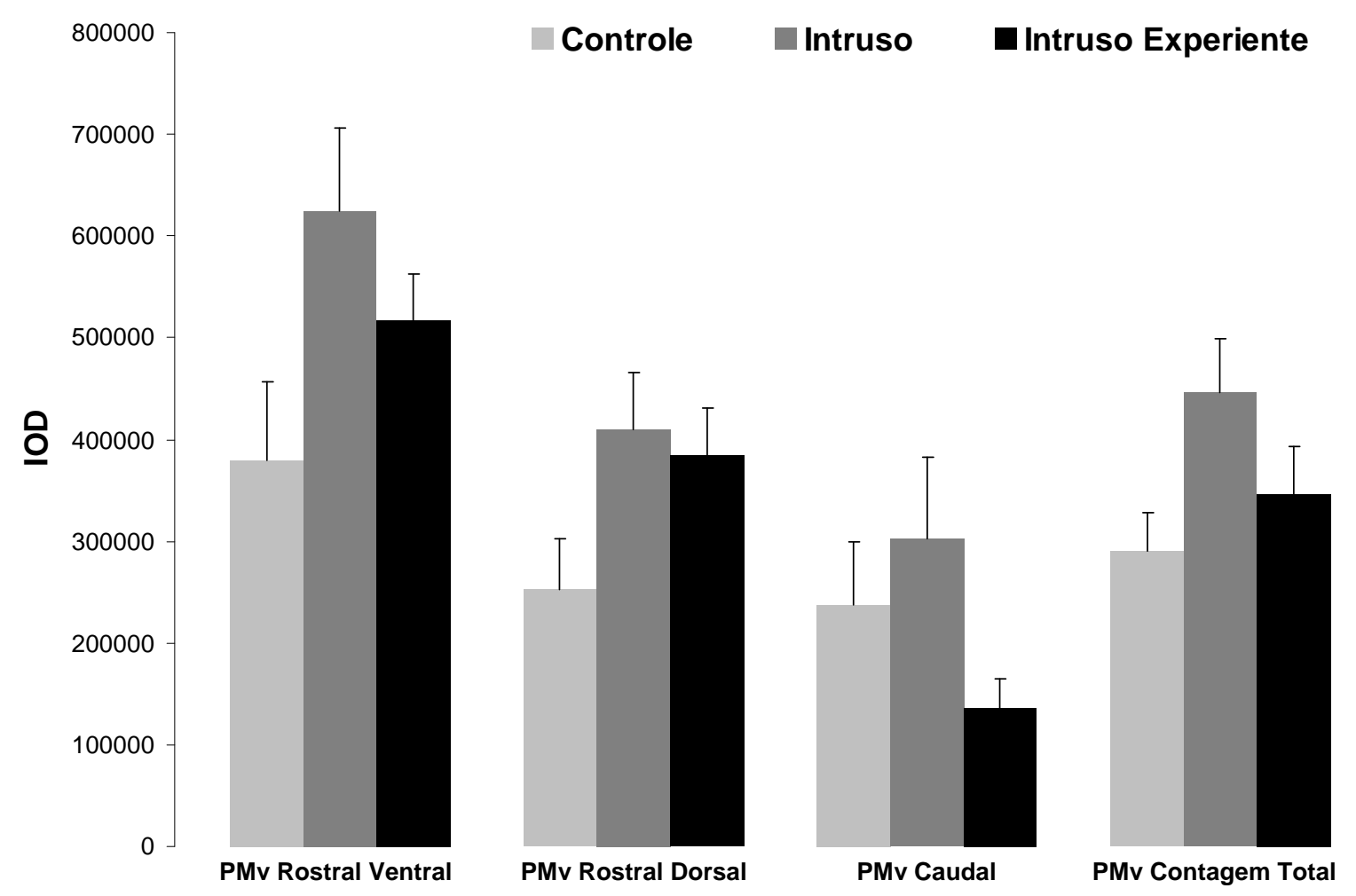

Figura 3 - Quantificação da densidade óptica integrada (IOD) resultante da Hibridização in situ para verificação da expressão de RNAm de nNOS no núcleo Pré-Mamilar ventral nas suas partes Rostral Ventral, Rostral Dorsal, Caudal e Contagem Total do núcleo. Dados apresentados como média ( \pm SEM). *, $p<0,05$ em relação a Intruso Experiente.

\subsection{ANÁLISE COMPORTAMENTAL}

Um rato intruso naive expressa, principalmente, comportamentos defensivos, que são, em sua maioria, posturas submissas como on the back, onde o animal se mantém deitado com o dorso voltado ao chão e o ventre exposto. Este animal, ainda, se mantém durante grande parte do tempo em freezing numa tentativa de diminuir a freqüência dos ataques (BLANCHARD et al., 1977; BLANCHARD; BLANCHARD, 1977).

Já, em animais intrusos que convivem com a fêmea e que apresentam experiência sexual prévia ao encontro agonístico, é possível observar que os comportamentos expressos são atípicos aos de um intruso naive. Foi observado nesse grupo diminuição das posturas submissas (On the back $\mathrm{H}(1,10)=6,82 \mathrm{p}<0,05$ e Upright $\mathrm{H}(1,10)=4,81 \mathrm{p}<0,05)$ e do comportamento de freezing $(\mathrm{H}(1,10)=7,76$ $p<0,05)$, e aumento da busca por contato com o residente (Contact $\mathrm{H}(1,10)=6,82$ $\mathrm{p}<0,05$ e Anogenital Sniffing $\mathrm{H}(1,10)=7,76 \mathrm{p}<0,05)$ que, ocasionalmente, resulta em 
comportamento de monta do intruso sobre o residente. Ainda é possível notar bater de cauda do intruso e o comportamento de ataque lateral deste ao residente $(H(1,10)=8,33 p<0,05)$, onde arqueia o dorso e se move lateralmente em direção a este. Isso sugere que a experiência sexual modifica o comportamento de forma ao animal não se apresentar subordinado, como é observado comumente em intrusos naive, e buscar pela dominância do território (ver Tabela 1 e Figura 4).

Este grupo também se difere dos animais que apresentam lesão no núcleo pré-mamilar dorsal, onde é possível observar a perda do medo ao residente, expresso por uma diminuição da resposta de defesa, com acentuada redução dos comportamentos de defesa passiva, isto é, freezing após o ataque do residente e quando este não se encontra em contato direto com o intruso. Já os comportamentos de defesa ativa não são alterados, esses são principalmente on the back e upright, que são expressos quando o residente se coloca ativamente em contato com o intruso, na tentativa de morder-lhe o dorso (MOTTA et al., 2009). Porém, neste grupo animal, não observamos comportamentos típicos de tentativa de dominância como monta e ataque lateral, nem bater de cauda, e diferentemente, nos intervalos dos ataques o intruso se dedica, apenas, a explorar o ambiente.

Tabela 1 - Análise comportamental dos grupos Intruso e Intruso experiente, durante período de 5 minutos de observação, após o ataque inicial do residente Os dados são apresentados como o número total de eventos realizados. *, p < 0,05 em relação à Intruso Experiente.

\begin{tabular}{c|c|c}
\hline & Intruso & Intruso Experiente \\
\hline Ataque Lateral & $0^{*}$ & 7 \\
\hline Monta & 0 & 3 \\
\hline
\end{tabular}




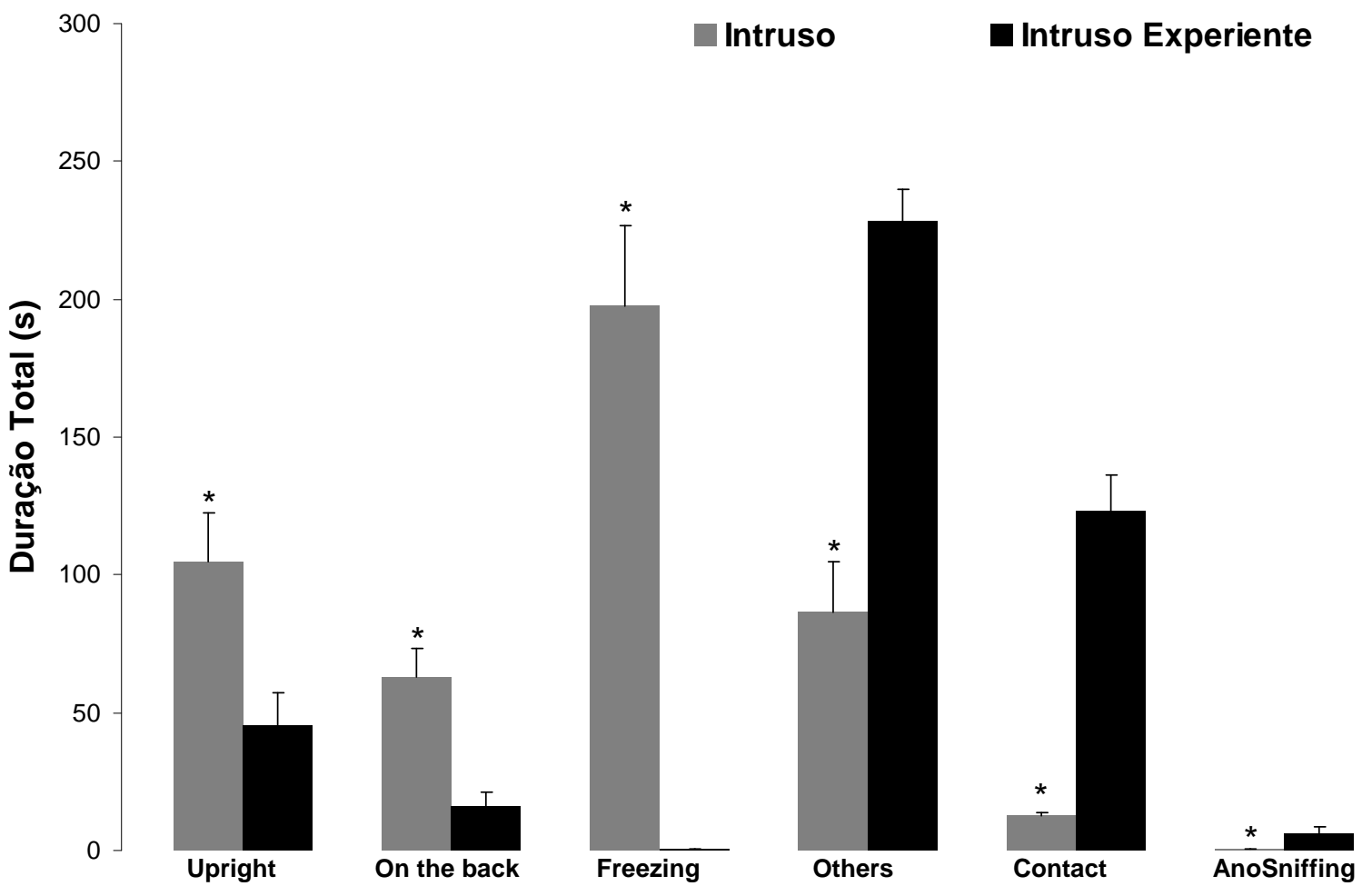

Figura 4 - Análise comportamental dos grupos Intruso e Intruso experiente durante período de 5 minutos de observação após o ataque inicial do residente. Os dados são apresentados como média $( \pm$ SEM). *, $p<0,05$ em relação à Intruso Experiente. 


\section{DISCUSSÃO}

O comportamento agressivo é etologicamente observado em animais e está relacionado com o estabelecimento de território e dominância sobre fêmeas férteis e sobre o grupo social em que o animal está inserido (PARMIGIANI et al., 1998; EIBLEIBESFELDT, 1977). Um animal dominante não é, necessariamente, o mais agressivo, pois a dominância não é definida pela quantidade de agressão, mas sim pela direção em que segue a agressividade (VELLUCCI, 1990; CRAIG, 1986). As posturas ofensivas, o maior tamanho dos dominantes e os dentes a mostra são formas de se mostrar superior aos demais e mantê-los em posição subordinada de forma passiva. Por outro lado, manter-se afastado e sem contato direto com o dominante inibe a agressão deste, levando a maior latência e menor número dos ataques ofensivos (VELLUCCI, 1990; CRAIG, 1986; BLANCHARD et al., 1977; BLANCHARD; BLANCHARD, 1977).

Para o estudo do comportamento agressivo, temos como ferramenta o paradigma residente-intruso, onde é possível observar a conduta agressiva do animal residente (dominante) bem como os comportamentos de defensa e submissão do animal intruso (subordinado) (BLANCHARD et al., 1977; BLANCHARD; BLANCHARD, 1977).

Em nosso trabalho, pudemos observar que os comportamentos expressos pelos animais intrusos que eram expostos à fêmea antes do encontro agonístico, e que apresentavam comportamento sexual prévio, eram diferentes dos de um intruso sem experiência sexual prévia (intruso naive). Nos intrusos sexualmente experientes não foram observados posturas de submissão, como postura on the back (ficar deitados com o dorso voltado ao chão e o ventre exposto), mas sim uma busca ativa pelo dorso do residente, e que por várias vezes resultavam em comportamento de monta, uma postura tipicamente vista durante a disputa de dominância. Estes intrusos experientes ainda apresentam ataque lateral, caracterizados por um movimento ao redor do residente com arqueamento do dorso e bater de cauda, que também são posturas claras de busca pela dominância. Isso sugere que a experiência sexual no intruso modifica o comportamento de forma que os animais perdem os comportamentos característicos de subordinação, e ao mesmo tempo disputam a dominância com o residente. 
Aqui é interessante relatarmos que estes comportamentos diferentemente dos animais intrusos com experiência sexual prévia, que aparentemente perdem os comportamentos de subordinação, intrusos com lesão do núcleo pré-mamilar dorsal (PMd) perdem o comportamento de defesa frente aos residentes (MOTTA et al., 2009). Assim, em trabalho prévio mostramos que intrusos com lesão do PMd diminuem drasticamente a resposta de defesa observado pela acentuada diminuição dos comportamentos de defesa passiva (tempo de congelamento após o ataque dos residentes). Contudo, estes animais apresentam comportamentos defensivos ativos, como evitação e boxing, e diferentemente dos intrusos com experiência sexual prévia não apresentam comportamento de monta ao residente ou ameaça lateral com bater da cauda, os quais indicam a busca pela dominância.

Desta forma, poderíamos concluir que circuitos distintos podem estar relacionados aos comportamentos de submissão e de defesa do intruso, onde o comportamento de defesa depende de um circuito que envolve o núcleo pré-mamilar dorsal (PMd) e suas projeções para a matéria cinzenta periaquedutal e o comportamento de submissão dependeria do núcleo pré-mamilar ventral, o que seria possível via suas projeções para elementos do circuito sexualmente dimórfico do hipotálamo (MOTTA et al., 2009; CANTERAS et al., 1992).

Nossos resultados revelaram um aumento significativo da expressão do RNAm do CART no PMv dos intrusos com experiência sexual prévia. Dados anteriores da literatura mostram que a exposição do cheiro de fêmea é suficiente para aumentar a expressão do RNAm do CART no PMv (CAVALCANTE et al., 2006). Esse aumento de expressão de neuropeptídeo parece ser específico uma vez que não foi observado alterações nos níveis de NOS nos grupos analisados.

Portanto, poderíamos assumir que a experiência sexual pode estar relacionada ao aumento da expressão do CART no PMv, e que possivelmente possa estar associada a perda dos comportamento de subordinação e aumento das tentativas de disputa pela dominância. Estudos adicionais são obviamente necessários para provar esta hipótese. 


\section{CONCLUSÃO}

No paradigma residente intruso, animais intrusos experientes sexualmente não se apresentam subordinados como fazem os intrusos naive e passam a adotar posturas de busca pela dominância do território. Estes animais, ainda, apresentam expressão elevada de CART no PMv quando comparados a intrusos naive e controle. Todavia, não foi notada diferença na expressão de NOS no PMv nos grupos supracitados, indicando que a elevação do neuropeptídeo CART é específica. Ainda, este aumento pode estar relacionado ao comportamento sexual, uma vez que as pistas olfativas da fêmea são suficientes para aumentar sua expressão, e a perda de submissão observada neste grupo experimental. Estudos futuros com silenciadores de CART ou com animais knockout seriam necessários para determinar com mais clareza essa relação. 


\section{REFERÊNCIAS}

ADAMS, D. Defense and territorial behaviour dissociated by hypothalamic lesions in the rat. Nature, v. 232, p. 573-574, 1971.

ALBERTS B.; JOHNSON,A.; LEWIS, J.; RAFF, M.; ROBERTS, K.; WALTER, P. Biologia Molecular da Célula. 4. ed. Porto Alegre: Artmed, 2004.

ALBERTSON, D.N.; PRUETZ, B.; SCHMIDT, C.J.; KUHN, D.M.; KAPATOS, G.; BANNON, M.J. Gene expression profile of the nucleus accumbens of human cocaine abusers: evidence for dysregulation of myelin. J. Neurochem., v. 88, n. 5, p. 12111219, 2004.

ASAKAWA, A.; INUI, A.; YUZURIHA, H.; NAGATA, T.; KAGA, T.; UENO, N.; FUJINO, M.A.; KASUGA, M. Cocaine-amphetamine-regulated transcript influences energy metabolism, anxiety and gastric emptying in mice. Horm. Metab. Res., v. 33, n. 9, p. 554-558, 2001.

BALKAN, B.; KOYLU, E.; POGUN, S.; KUHAR M.J. Effects of adrenalectomy on CART expression in the rat arcuate nucleus. Synapse, v. 50, n. 1, p. 14-19, 2003.

BANNON, A.W.; SEDA, J.; CARMOUCHE, M.; FRANCIS, J.M.; JAROSINSKI, M.A.; DOUGLASS, J. Multiple behavioral effects of cocaine- and amphetamine-regulated transcript (CART) peptides in mice: CART 42-89 and CART 49-89 differ in potency and activity. J. Pharmacol. Exp. Ther., v. 299, n. 3, p. 1021-1026, 2001.

BEAUDRY, G.; ZEKKI, H.; ROUILLARD, C.; LÉVESQUE, D. Clozapine and dopamine D3 receptor antisense reduce cocaine- and amphetamine-regulated transcript expression in the rat nucleus accumbens shell. Synapse, v. 51, n. 4, p. 233-240, 2004.

BLANCHARD, R.J.; BLANCHARD, D.C.; TAKAHASHI, T.; KELLEY, M.J. Attack and defensive behaviour in the albino rat. Anim. Behav., v. 25, n. 3, p. 622-634, 1977.

BLANCHARD, R.J.; BLANCHARD, D.C. Aggressive behavior in the rat. Behav. Biol., v. 21, n. 2, p. 197-224, 1977.

BOISSEL, J.P.; SCHWARZ, P.M.; FÖRSTERMANN, U. Neuronal-type NO synthase: transcript diversity and expressional regulation. Nitric Oxide, v. 2, n. 5, p. 337-349, 1998.

De acordo com:

ASSOSIAÇÃO BRASILEIRA DE NORMAS E TÉCNICAS. NBR 6023: Informação e documentação: referências: elaboração. Rio de Janeiro, 2002. 
BREDT, D.S. Endogenous nitric oxide synthesis: biological functions and pathophysiology. Free Radic. Res., v. 31, n. 6, p. 577-596, 1999.

CANTERAS, N.S.; SIMERLY, R.B.; SWANSON, L.W. Projections of the ventral premammillary nucleus. J. Comp. Neurol., v. 324, n. 2, p. 195- 212, 1992.

CAVALCANTE, J.C.; BITTENCOURT, J.C.; ELIAS, C.F. Female odors stimulate CART neurons in the ventral premammillary nucleus of male rats. Physiol. Behav., v. 88, n. 1-2, p. 160-166, 2006.

CHAKI, S.; KAWASHIMA, N.; SUZUKI, Y.; SHIMAZAKI, T.; OKUYAMA, S. Cocaineand amphetamine-regulated transcript peptide produces anxiety-like behavior in rodents. Eur. J. Pharmacol., v.464, n. 1, p. 49-54, 2003.

CLARK, J.T.; KALRA, P.S.; CROWLEY, W.R.; KALRA, S.P. Neuropeptide $Y$ and human pancreatic polypeptide stimulate feeding behavior in rats. Endocrinology, $v$. 115, n. 1, 427-429, 1984.

CRAIG, J.V. Measuring social behavior: social dominance. J. Anim. Sci., v. 62, n. 4, p. 1120-1129, 1986.

DALLVECHIA-ADAMS, S.; KUHAR, M.J.; SMITH, Y. Cocaine- and amphetamineregulated transcript peptide projections in the ventral midbrain: colocalization with gamma-aminobutyric acid, melanin-concentrating hormone, dynorphin, and synaptic interactions with dopamine neurons. J. Comp. Neurol., v. 448, n. 4, p. 360-372, 2002.

DALLVECHIA-ADAMS, S.; SMITH, Y.; KUHAR, M.J. CART peptide-immunoreactive projection from the nucleus accumbens targets substantia nigra pars reticulata neurons in the rat. J. Comp. Neurol., v. 434, n. 1, p. 29-39, 2001.

DOMINGUEZ, G.; VICENTIC, A.; DEL GIUDICE, E.M.; JAWORSKI, J.; HUNTER, R.G.; KUHAR, M.J. CART peptides: modulators of mesolimbic dopamine, feeding, and stress. Ann. N.Y. Acad. Sci., v. 1025, p. 363-369, 2004.

DOUGLASS, J.; MCKINZIE, A.A.; COUCEYRO, P. PCR differential display identifies a rat brain mRNA that is transcriptionally regulated by cocaine and amphetamine. $\mathbf{J}$. Neurosci., v. 15, n. 3, p. 2471-2481, 1995.

EIBL-EIBESFELDT, I. Evolution of destructve aggression. Aggress. Behav., v. 3, p. 127-144, 1977. 
ELIAS, C.F.; KELLY, J.F.; LEE, C.E.; AHIMA, R.S.; DRUCKER, D.J.; SAPER, C.B.; ELMQUIST, J.K. Chemical characterization of leptin-activated neurons in the rat brain. J. Comp. Neurol., v. 423, n. 2, p. 261-281, 2000.

ELIAS, C.F.; LEE, C.; KELLY, J.; ASCHKENASI, C.; AHIMA, R.S.; COUCEYRO, P.R.; KUHAR, M.J.; SAPER, C.B.; ELMQUIST, J.K. Leptin activates hypothalamic CART neurons projecting to the spinal cord. Neuron, v. 21, n. 6, p. 1375-1385, 1998.

FLANNELLY, K.J.; BLANCHARD, R.J.; MURAOKA, M.Y.; FLANNELLY, L. Copulation increases offensive attack in male rats. Physiol. Behav., v. 29, n. 2, p. 381-385, 1982.

GOYENS, J.; NOIROT, E. Effects of cohabitation with females on aggressive behavior between male mice. Dev. Psychobiol., v. 8, n. 1, p. 79-84, 1975.

HUBERT, G.W.; KUHAR, M.J. Colocalization of CART peptide with prodynorphin and dopamine D1 receptors in the rat nucleus accumbens. Neuropeptides, v. 40, n. 4, p. 409-415, 2006.

JAWORSKI, J.N.; HANSEN, S.T.; KUHAR, M.J.; MARK, G.P. Injection of CART (cocaine- and amphetamine-regulated transcript) peptide into the nucleus accumbens reduces cocaine self-administration in rats. Behav. Brain Res., v. 191, n. 2, p. 266-671, 2008.

JAWORSKI, J.N.; KOZEL, M.A.; PHILPOT, K.B.; KUHAR, M.J. Intra-accumbal injection of CART (cocaine-amphetamine regulated transcript) peptide reduces cocaine-induced locomotor activity. J. Pharmacol. Exp. Ther., v. 307, n. 3, p. 10381044, 2003.

KAMEL, F.; WRIGHT, W.W.; MOCK, E.J.; FRANKEL, A.I. The influence of mating and related stimuli on plasma levels of luteinizing hormone, follicle stimulating hormone, prolactin, and testosterone in the male rat. Endocrinology, v. 101, n. 2, p. 421-429, 1977.

KASK, A.; SCHIÖTH, H.B.; MUTULIS, F.; WIKBERG, J.E.; RÄGO, L. Anorexigenic cocaine- and amphetamine-regulated transcript peptide intensifies fear reactions in rats. Brain Res., v. 857, n. 1-2, p. 283-285, 2000.

KIM, J.H.; CREEKMORE, E.; VEZINA, P. Microinjection of CART peptide 55-102 into the nucleus accumbens blocks amphetamine-induced locomotion. Neuropeptides, $v$. 37, n. 6, p. 369-373, 2003. 
KIMMEL, H.L.; GONG, W.; VECHIA, S.D.; HUNTER, R.G.; KUHAR, M.J. Intraventral tegmental area injection of rat cocaine and amphetamine-regulated transcript peptide 55-102 induces locomotor activity and promotes conditioned place preference. J. Pharmacol. Exp. Ther., v. 294, n. 2, p. 784-792, 2000.

KOLLACK-WALKER, S.; NEWMAN, S.W. Mating and agonistic behavior produce different patterns of Fos immunolabeling in the male Syrian hamster brain. Neuroscience, v. 66, n. 3, p. 721-736, 1995.

KOLLACK-WALKER, S.; WATSON, S.J.; AKIL, H. Social stress in hamsters: defeat activates specific neurocircuits within the brain. J. Neurosci., v. 17, n. 22, p. 88428855, 1997.

KOOLHAAS, J.M. Hypothalamically induced intraspecific aggressive behaviour in the rat. Exp. Brain Res., v. 32, n. 3, p. 365-375, 1978.

KOYLU, E.O.; BALKAN, B.; KUHAR, M.J.; POGUN, S. Cocaine and amphetamine regulated transcript (CART) and the stress response. Peptides, v. 27, n. 8, p. 19651969, 2006.

KOYLU, E.O.; COUCEYRO, P.R.; LAMBERT, P.D.; KUHAR, M.J. Cocaine- and amphetamine-regulated transcript peptide immunohistochemical localization in the rat brain. J. Comp. Neurol., v. 391, n. 1, p. 115-132, 1998.

KOYLU, E.O.; COUCEYRO, P.R.; LAMBERT, P.D.; LING, N.C.; DESOUZA, E.B.; KUHAR, M.J. Immunohistochemical localization of novel CART peptides in rat hypothalamus, pituitary and adrenal gland. J. Neuroendocrinol., v. 9, n. 11, p. 823833, 1997.

KOYLU, E.O.; WERUAGA, E.; BALKAN, B.; ALONSO, J.R.; KUHAR, M.J.; POGUN, S. Co-localization of cart peptide immunoreactivity and nitric oxide synthase activity in rat hypothalamus. Brain Res., v. 868, n. 2, p. 352-357, 2000.

KRISTENSEN, P.; JUDGE, M.E.; THIM, L.; RIBEL, U.; CHRISTJANSEN, K.N.; WULFF, B.S.; CLAUSEN, J.T.; JENSEN, P.B.; MADSEN, O.D.; VRANG, N.; LARSEN, P.J.; HASTRUP, S. Hypothalamic CART is a new anorectic peptide regulated by leptin. Nature, v. 393, n. 6680, p. 72-76, 1998.

KUHAR, M.J.; ADAMS, L.D.; HUNTER, R.G.; VECHIA, S.D.; SMITH, Y. CART Peptides. Regul. Pept., v. 89, n. 1-3, p. 1-6, 2000.

KUHAR, M.J.; ADAMS, S.; DOMINGUEZ, G.; JAWORSKI, J.; BALKAN, B. CART peptides. Neuropeptides, v. 36, n. 1, p. 1-8, 2002. 
LAMBERT, P.D.; COUCEYRO, P.R.; MCGIRR, K.M.; DALL VECHIA, S.E.; SMITH, Y.; KUHAR, M.J. CART peptides in the central control of feeding and interactions with neuropeptide Y. Synapse, v. 29, n. 4, p. 293-298, 1998.

LARSEN, P.J.; SEIER, V.; FINK-JENSEN, A.; HOLST, J.J.; WARBERG, J.; VRANG, $\mathrm{N}$. Cocaine- and amphetamine-regulated transcript is present in hypothalamic neuroendocrine neurones and is released to the hypothalamic-pituitary portal circuit. J. Neuroendocrinol., v. 15, n. 3, p. 219-226, 2003.

LARSEN, P.J.; VRANG, N.; PETERSEN, P.C.; KRISTENSEN, P. Chronic intracerebroventricular administration of recombinant CART(42-89) peptide inhibits and causes weight loss in lean and obese Zucker (fa/fa) rats. Obes. Res., v. 8, n. 8, p. 590-596, 2000.

LÓPEZ-FIGUEROA, M.O.; DAY, H.E.; AKIL, H.; WATSON, S.J. Nitric oxide in the stress axis. Histol. Histopathol., v. 13, n. 4, p. 1243-1252, 1998.

MACRIDES, F.; BARTKE, A.; DALTERIO, S. Strange females increase plasma testosterone levels in male mice. Science, v. 189, n. 4208, p. 1104-1106, 1975.

MARIE-CLAIRE, C.; LAURENDEAU, I.; CANESTRELLI, C.; COURTIN, C.; VIDAUD, M.; ROQUES, B.; NOBLE, F. Fos but not Cart (cocaine and amphetamine regulated transcript) is overexpressed by several drugs of abuse: a comparative study using real-time quantitative polymerase chain reaction in rat brain. Neurosci. Lett., v. 345, n. 2, p. 77-80, 2003.

MCCANN, S.M.; KARANTH, S.; KIMURA, M.; YU, W.H.; RETTORI, V. The role of nitric oxide (NO) in control of hypothalamic-pituitary function. Rev. Bras. Biol., v. 56, n. 1, p. 105-112, 1996.

MOTTA, S.C.; GOTO, M.; GOUVEIA, F.V.; BALDO, M.V.C.; CANTERAS, N.S.; SWANSON, L. Dissecting the brain's fear system: the hypothalamus is critical for responding in rival conspecific intruders. Proc. Natl. Acad. Sci. U.S.A., v. 106, n. 12, p. 4870-4875, 2009.

NELSON, R.J.; DEMAS, G.E.; HUANG, P.L.; FISHMAN, M.C.; DAWSON, V.L.; DAWSON, T.M.; SNYDER, S.H. Behavioural abnormalities in male mice lacking neuronal nitric oxide synthase. Nature, v. 378, n. 6555, p. 383-386, 1995.

OLIVIER, B.; OLIVIER-AARDEMA, R.; WIEPKEMA, P.R. Effects of anterior hypothalamic and mammilary area lesions on territorial aggressive behaviour in male rats. Behav. Brain Res., v. 9, p. 59-81, 1983. 
OLIVIER, B. The ventromedial hypothalamus and aggressive behavior in rats. Aggress. Behav., v. 3, p. 47-56, 1977.

PARMIGIANI, S.; FERRARI, P.F.; PALANZA, P. An evolutionary approach to behavioral pharmacology: using drugs to understand proximate and ultimate mechanisms of different forms of aggression in mice. Neurosci. Biobehav. Rev., v. 23, n. 2, p. 143-153, 1998.

PETTIT, H.O.; PAN, H.T.; PARSONS, L.H.; JUSTICE, J.B. Extracellular concentrations of cocaine and dopamine are enhanced during chronic cocaine administration. J. Neurochem., v. 55, n. 3, p. 798-804, 1990.

PURVIS, K.; HAYNES, N.B. Effect of the odour of female rat urine on plasma testosterone concentrations in male rats. J. Reprod. Fertil., v. 53, n. 1, p. 63-65, 1978.

RANG, H.P.; DALE, M.M.; RITTER, J.M.; MOORE, P.K. Farmacologia. 5. ed. Rio de Janeiro: Elsevier, 2004. Tradução da $5^{\circ}$ edição americana.

ROELING, T.A.; VEENING, J.G.; KRUK, M.R.; PETERS, J.P.; VERMELIS, M.E.; NIEUWENHUYS, R. Efferent connections of the hypothalamic "aggression area" in the rat. Neuroscience, v. 59, n. 4, p. 1001-1024, 1994.

ROGGE, G.; JONES, D.; HUBERT, G.W.; LIN, Y.; KUHAR, M.J. CART peptides: regulators of body weight, reward and other functions. Nature reviews. Neuroscience, v. 9, n. 10, p. 747-758, 2008.

RONDINI, T.A.; BADDINI, S.P.; SOUSA, L.F.; BITTENCOURT, J.C.; ELIAS, C.F. Hypothalamic cocaine- and amphetamine-regulated transcript neurons project to areas expressing gonadotropin releasing hormone immunoreactivity and to the anteroventral periventricular nucleus in male and female rats. Neuroscience, v. 125, n. 3, p. 737-748, 2004.

SAVONTAUS, E.; CONWELL, I.M.; WARDLAW, S.L. Effects of adrenalectomy on AGRP, POMC, NPY and CART gene expression in the basal hypothalamus of fed and fasted rats. Brain Res., v. 958, n. 1, p. 130-138, 2002.

SMITH, S.M.; VAUGHAN, J.M.; DONALDSON, C.J.; RIVIER, J.; LI, C.; CHEN, A.; VALE, W.W. Cocaine- and Amphetamine-Regulated Transcript Activates the Hypothalamic-Pituitary-Adrenal Axis through a Corticotropin-Releasing Factor Receptor-Dependent Mechanism. Endocrinology, v. 145, n. 11, p. 5202-5209, 2004. 
SMITH, Y.; KIEVAL, J.; COUCEYRO, P.R.; KUHAR, M.J. CART peptideimmunoreactive neurones in the nucleus accumbens in monkeys: ultrastructural analysis, colocalization studies, and synaptic interactions with dopaminergic afferents. J. Comp. Neurol., v. 407, n. 4, p. 491-511, 1999.

SPIESS, J.; VILLARREAL, J.; VALE, W. Isolation and sequence analysis of a somatostatin-like polypeptide from ovine hypothalamus. Biochemistry, v. 20, n. 7, p. 1982-1988, 1981.

STANLEY, S.A.; SMALL, C.J.; MURPHY, K.G.; RAYES, E.; ABBOTT, C.R.; SEAL, L.J.; MORGAN, D.G.; SUNTER, D.; DAKIN, C.L.; KIM, M.S.; HUNTER, R.; KUHAR, M.; GHATEI, M.A.; BLOOM, S.R. Actions of cocaine- and amphetamine-regulated transcript (CART) peptide on regulation of appetite and hypothalamo-pituitary axes in vitro and in vivo in male rats. Brain Res., v. 893, n. 1-2, p. 186-194, 2001.

TANG, W.X.; FASULO, W.H.; MASH, D.C.; HEMBY, S.E. Molecular profiling of midbrain dopamine regions in cocaine overdose victims. J. Neurochem., v. 85, n. 4, p. 911-924, 2003.

VAN DEN BERG, M.J.; HORST, G.J.; KOOLHAAS, J.M. The nucleus premammillaris ventralis (PMV) and Aggressive Behavior in the rat. Aggress. Behav., v. 9, p. 41-47, 1983.

VELLUCCI, S.V. Primate social behavior--anxiety or depression? Pharmacol. Ther., v. 47, n. 2, p. 167-180, 1990.

VICENTIC, A.; HUNTER, R.G.; KUHAR, M.J. Effect of corticosterone on CART peptide levels in rat blood. Peptides, v. 26, n. 3, p. 531-533, 2005.

VINCENT, S.R.; KIMURA, H. Histochemical mapping of nitric oxide synthase in the rat brain. Neuroscience, v. 46, n. 4, p. 755-784, 1992.

VRANG, N.; LARSEN, P.J.; KRISTENSEN, P.; TANG-CHRISTENSEN, M. Central administration of cocaine-amphetamine-regulated transcript activates hypothalamic neuroendocrine neurons in the rat. Endocrinology, v. 141, n. 2, p. 784-801, 2000.

VRANG, N.; LARSEN, P.J.; KRISTENSEN, P.; Cocaine-amphetamine regulated transcript (CART) expression is not regulated by amphetamine. Neuroreport, v. 13, n. 9, p. 1215-1218, 2002. 
VRANG, N.; LARSEN, P.J.; TANG-CHRISTENSEN, M.; LARSEN, L.K.; KRISTENSEN, P. Hypothalamic cocaine-amphetamine regulated transcript (CART) is regulated by glucocorticoids. Brain Res., v. 965, n. 1-2, p. 45-50, 2003.

VRANG, N. Anatomy of hypothalamic CART neurons. Peptides, v. 27, n. 8, p. 19701980, 2006.

ZHOU, L.; ZHU, D.Y. Neuronal nitric oxide synthase: structure, subcellular localization, regulation, and clinical implications. Nitric Oxide, v. 20, n. 4, p. 223-230, 2009. 